\title{
cMaJPPEN
}

\section{Access to sexual and reproductive health care among young adult sex workers in Toronto, Ontario: a mixed-methods study}

\author{
Lori E. Ross PhD, Andrea Sterling MA, Cheryl Dobinson MA, Carmen H. Logie MSW PhD, \\ Sandra D'Souza MPH
}

\section{Abstract}

Background: Young adult sex workers may benefit from sexual and reproductive health care services; however, little research has examined their access experiences. This study aimed to assess barriers to and facilitators of access to sexual and reproductive health care among young adult sex workers, and identify practices suggested by participants to improve services.

Methods: This was a community-based mixed-methods study of adults aged 18-29 years who were currently or had previously been engaged in sex work, conducted in Toronto in 2017-2018. The study was guided by a Youth Advisory Committee of 4 youth with lived experience of sex work. Participants completed an online survey, or participated in a focus group or a one-on-one interview; all 3 modalities included parallel questions about barriers to and facilitators of access to sexual and reproductive health care. We summarized quantitative data using descriptive statistics and identified qualitative themes using thematic analysis, followed by triangulation of the 2 strands.

Results: There were 54 survey respondents (response rate $48 \%$ ) and 17 participants in the qualitative phase (14 in focus groups and 3 in interviews), for a total sample size of 71 . Survey respondents reported suboptimal access to sexual and reproductive health care, with $8(15 \%)$ reporting no regular source of care, and only $6(11 \%)$ reporting that they disclose their sex work experience to providers. Actual or expected stigma regarding sex work on the part of providers was the dominant barrier to care, whereas nonjudgmental providers, particularly those who themselves have sex work experience, was a key facilitator. Participants suggested 7 practices to improve access to sexual and reproductive health care.

Interpretation: Young adult sex workers face many barriers to accessing sexual and reproductive health care. Including people with sex work experience in the development of solutions will maximize the capacity to address the needs of this underserved population.

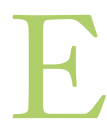

ngagement in sex work (the exchange of sexual services for money, services or goods) is associated with a higher chance of contact with sexually transmitted and blood-borne infections including HIV, both in Canada and globally., Although participation in sex with multiple partners, exposure to sexual violence, intravenous drug use, an unstable living environment and a criminalized working environment are contributors to this elevated risk for some sex workers, stigma in health care settings also contributes to inadequate access to health care services. ${ }^{1}$ Sex workers have reported a variety of reasons for not seeking health care, and stigma associated with sex work appears to be a primary barrier. ${ }^{3,4}$

Young adults (aged 18-29 yr) who engage in sex work appear to be particularly at risk for HIV and other infections and associated risk factors. ${ }^{5}$ These risks, particularly among youth, are a major concern given the well-established longterm health impacts of untreated sexually transmitted infections. ${ }^{6-8}$ However, we could identify no Canadian research that has specifically examined the experiences of young adult sex workers in Canada in accessing sexual and reproductive health care services.

In a recent local needs assessment of the experiences of youth in Toronto, Ontario, with sexual health care services, respondents who reported experience with sex work were more likely than other youth to cite unmet sexual health needs and to lack access to sexual health information and services. ${ }^{9}$ To address this local need and the gap in Canadian research more broadly, we conducted a study to address the following research questions: 1) What are the barriers to and

\section{Competing interests: None declared.}

This article has been peer reviewed.

Correspondence to: Lori Ross, I.ross@utoronto.ca

CMAJ Open 2021. DOI:10.9778/cmajo.20200049 
facilitators of access to sexual and reproductive health care services for young adult sex workers? and 2) What practices do young adult sex workers suggest to improve access to health care for this population?

\section{Methods}

\section{Setting and design}

This research was carried out in Toronto, Canada's most populous urban centre. Although no data are available to quantify the prevalence of sex work in the city, it hosts an active community of sex workers and organizations to support those involved in sex work. Furthermore, Toronto is home to many youth living in high-risk situations, with data suggesting that nearly one-third of homeless people in the city are youth. ${ }^{10}$ As such, we would expect a large population of young adult sex workers in Toronto.

This mixed-methods study included 2 strands: a quantitative Internet-based cross-sectional survey, and qualitative focus groups and interviews. As such, it was conducted according to the STROBE cross-sectional reporting guidelines, the Consolidated Criteria for Reporting Qualitative Research Checklist (COREQ) and the Checklist for Reporting Results of Internet E-Surveys (CHERRIES). ${ }^{11-13}$

We used a community-based participatory research design wherein the study was designed and carried out in its entirety in close collaboration with people with lived experience of sex work, as facilitated through a partnership with Maggie's Toronto Sex Workers Action Project. ${ }^{14}$ The study further drew from a transformative mixed-methods study design wherein an explicit social justice aim (to improve access to health care services for young adult sex workers) underpinned the rationale for a mixed-methods approach..$^{15}$ Embedded within this transformative design was a convergent mixedmethods study design wherein both qualitative (thematic analysis) and quantitative (cross-sectional survey) methods were used to address the same research questions. ${ }^{15}$

Although the research questions were best addressed by means of qualitative methods, representatives from Maggie's Toronto Sex Workers Action Project identified that participation in focus groups or interviews might involve more identity disclosure than some young adult sex workers would be comfortable with. Thus, to reduce selection bias, participants had the option of participating in a single semistructured focus group lasting 1.5-2 hours, a semistructured individual interview lasting 1-1.5 hours or an anonymous online survey administered with the use of the application Qualtrics. All 3 modalities included parallel questions regarding barriers to and facilitators of access to health care services and suggestions for improvement.

The study was guided by a Youth Advisory Committee of 4 youth with lived experience of sex work. We recruited the committee members by posting flyers at community organizations frequented by young adult sex workers, and through online flyers circulated through email lists and social media outlets directed toward sex workers. Members were involved throughout the project, including providing feedback on recruitment materials and methods, distributing recruitment materials through their networks, reviewing and pilot testing the survey and the interview and focus group questions to reduce measurement bias, providing feedback on the coding framework to maximize credibility of findings, and participating in knowledge-exchange activities.

\section{Participants}

Eligible participants were young adults (aged 18-29 yr) who had previously been or were currently engaged in sex work. Those who had previously been involved in sex work had to be at least 18 years old at study participation. We set this age criterion because, given the current legal context in Canada, there could be serious legal or child welfare implications for those less than age 18 who were to report involvement in sex work, and we did not want to put our participants at risk for these implications. However, we wanted to provide opportunities for those who had sold or traded sex before age 18 to share their experiences in our study.

Recruitment was via convenience sampling, predominantly through online networks; recruitment flyers were also posted at locations likely to be frequented by sex workers. Two rounds of recruitment were carried out, 1 for either strand of the study. Potential participants could choose which strand they preferred to participate in. Recruitment materials instructed interested participants to contact the research coordinator for more information on the focus groups and interviews, or to visit the study Web page to complete the online survey.

\section{Measures}

The survey was developed on the basis of a survey previously administered by one of the authors (C.D.) for assessment of sexual and reproductive health care needs of youth in Toronto. ${ }^{9}$ We modified the original survey to address sexual and reproductive health issues expected to be of particular relevance to sex workers. After pilot testing with members of the Youth Advisory Committee, we made minor changes to wording and the order of questions, and added additional response options for some questions. The final survey included 1-4 items per page distributed over 22 screens (including those for the information letter and consent) (Appendix 1, available at www.cmajopen.ca/content/9/2/E482/suppl/DC1). Respondents were able to skip questions, and to review and change their responses using the "back" button.

Development of the guide for the focus groups and interviews followed survey development, with areas of questioning parallel to those included in the survey (i.e., barriers, facilitators and practice suggestions) but revised to be appropriate for the open-ended format of a qualitative interview (Appendix 2, available at www.cmajopen.ca/content/9/2/E482/suppl/DC1). The guide was developed by the research team, reviewed by members of the Youth Advisory Committee, and then revised according to their feedback. The guide was further revised as necessary after each interview and focus group to incorporate emerging themes. No formal pilot testing of the guide was conducted. 


\section{Outcomes}

The outcome variables of interest were barriers to and facilitators of access to sexual and reproductive health care reported by participants, assessed both qualitatively and quantitatively. Our exposure variable was self-reported current or past engagement in sex work between the ages of 18 and 29 years.

\section{Data collection}

Interviews and focus groups were conducted between October and December 2017 by a member of the research team who identified as a woman, held a graduate degree, had lived experience as a sex worker, had been involved in community activism with the sex work community and had previous experience conducting qualitative research interviews with sex workers. Only 1 of the participants in the qualitative strand (interview) was known to the interviewer before the study. In the interviews and focus groups, the interviewer introduced herself as a graduate student who had been extensively involved with sex work communities; she disclosed her own personal sex work experience only if it came up organically in the course of the interview or focus group. Focus groups and interviews were conducted at one of the community partner agencies, a university office or the participant's home, and no one other than the interviewer and participants were present. After each interview and focus group, the interviewer recorded brief field notes that pertained mostly to the interview guide (e.g. changes to wording, order of questions).

The target sample size for the qualitative strand was 24 participants, which we determined on the basis of our previous experience using thematic analysis to address research questions of a similar nature.

The survey was open between January and March 2018. The target sample size for the survey was 50 participants; however, we included all participants who could be recruited during this period. Qualitative data collection preceded quantitative data collection for feasibility reasons (limited project staffing). The recruitment period overlapped exactly with the data collection period for the 2 strands.

Before the focus group or interview began, participants provided verbal consent to participate and completed a demographic questionnaire. They received a cash honorarium of \$20 plus public transit tokens. Survey participants were required to tick a box indicating their consent to participate before proceeding to the online survey questions. No honorarium was provided for survey participation.

\section{Data analysis}

Interviews and focus groups were audiorecorded and transcribed verbatim. Participants did not have an opportunity to review transcripts given that our research ethics protocol required that participant contact information be destroyed immediately after data collection.

All members of the research team independently coded the first 2 transcripts to develop a preliminary coding framework (Appendix 3, available at www.cmajopen.ca/content/9/2/E482/ suppl/DC1), which incorporated themes determined in advance (e.g., barriers and facilitators) and themes derived from the data (e.g., provider stigma). Subsequent transcripts were coded independently by the interviewer and 1 other member of the research team using an iterative thematic analysis approach. ${ }^{16}$ All members of the research team who participated in coding had prior experience with thematic analysis. We used NVivo version 12 (QSR International) for data management.

The quantitative survey data were exported into SPSS Statistics version 26 (IBM Corporation) for analysis, which entailed computing descriptive statistics and proportions for the outcome and exposure variables.

Consistent with a convergent parallel design, qualitative and quantitative data were analyzed independently and in parallel, after which key dimensions were identified on which to compare the findings (specifically, barriers to and facilitators of access to sexual and reproductive health care services, and suggested practices to improve service delivery). We then compared findings on these dimensions using written summaries to allow for joint interpretation of the data.

\section{Ethics approval}

The study was approved by the University of Toronto Health Sciences Research Ethics Board.

\section{Results}

Of the 112 people who accessed the survey, 83 indicated their consent to participate on the first page of the survey, and 54 ( $48 \%$ of those who accessed the first page of the survey) met the screening criteria and provided sufficient data for analysis (i.e., answered the survey questions pertaining to the primary outcome variables). Twenty-one people contacted the research coordinator to participate in a focus group or interview; none refused to participate, and none withdrew after providing consent, although 4 did not ultimately attend a focus group or interview because of scheduling or other reasons. Fourteen people participated in focus groups, and 3 people participated in interviews, for a total of 17 participants in the qualitative strand. Focus groups lasted 80-124 minutes, and interviews lasted 48-60 minutes. Participant demographic characteristics are provided in Table 1.

Thematic saturation was reached during the final round of transcript analysis.

\section{Access to sexual and reproductive health care}

Twenty survey respondents (37\%) reported that they usually accessed sexual and reproductive health care at a family doctor's office. Other sources of health care included clinics (28 respondents [52\%]) and community health centres (24 [44\%]); 8 respondents (15\%) reported not having a regular source of health care. Six respondents (11\%) reported that they disclose their involvement in sex work to health care providers, 24 (44\%) reported that they sometimes disclose, and $24(44 \%)$ indicated that they never disclose. Less than onethird (17 [31\%]) agreed or strongly agreed that they had access to all of the sexual and reproductive health care services and programs they needed. The majority of participants 
Table 1: Demographic characteristics of study participants

\begin{tabular}{|c|c|c|c|}
\hline \multirow[b]{2}{*}{ Characteristic } & \multicolumn{3}{|c|}{ No. (\%) of participants* } \\
\hline & $\begin{array}{l}\text { Quantitative strand } \\
\qquad n=54\end{array}$ & $\begin{array}{l}\text { Qualitative strand } \\
\qquad n=17 \dagger\end{array}$ & $\begin{array}{l}\text { Overall sample } \\
\quad n=71\end{array}$ \\
\hline Mean age (range), yr & $25.6^{\star \star}(18-29)$ & 25.7 (19-29) & $20.9(18-29)$ \\
\hline $\begin{array}{l}\text { Mean age at first sex work } \\
\text { involvement (range), yr }\end{array}$ & $19.8+†(9-28)$ & $20.4 \dagger †(15-27)$ & $19.9(9-28)$ \\
\hline \multicolumn{4}{|l|}{ Currently involved in sex work } \\
\hline Yes & $33(61)$ & $14(82)$ & $47(66)$ \\
\hline No & $21(39)$ & $2(12)$ & $23(32)$ \\
\hline No response & $0(0)$ & $1(6)$ & $1(1)$ \\
\hline \multicolumn{4}{|l|}{ Racial/ethnic identity $\ddagger$} \\
\hline White & $32(59)$ & $15(88)$ & $47(66)$ \\
\hline Indigenous & $5(9)$ & $1(6)$ & $6(8)$ \\
\hline Black & $4(7)$ & $0(0)$ & $4(6)$ \\
\hline Other§ & $9(17)$ & $1(6)$ & $10(14)$ \\
\hline No response & $10(18)$ & $0(0)$ & $10(14)$ \\
\hline \multicolumn{4}{|l|}{ Gender identity $\ddagger$} \\
\hline Woman/female & $32(59)$ & $15(88)$ & $47(66)$ \\
\hline Nonbinary identity & $11(20)$ & $0(0)$ & $11(15)$ \\
\hline Genderfluid/genderqueer & $3(6)$ & $1(6)$ & $4(6)$ \\
\hline Trans & $3(6)$ & $0(0)$ & $3(4)$ \\
\hline Two-spirit & $2(4)$ & $0(0)$ & $2(3)$ \\
\hline Male & $1(2)$ & $1(6)$ & $2(3)$ \\
\hline Femme & $1(2)$ & $0(0)$ & $1(1)$ \\
\hline No response & $9(17)$ & $0(0)$ & $9(13)$ \\
\hline \multicolumn{4}{|l|}{ Sexual identity $\ddagger$} \\
\hline Queer & $17(31)$ & $7(41)$ & $24(34)$ \\
\hline Bisexual & $15(28)$ & $5(29)$ & $20(28)$ \\
\hline Straight/heterosexual & $9(17)$ & $4(24)$ & $13(18)$ \\
\hline Pansexual & $9(17)$ & $1(6)$ & $10(14)$ \\
\hline Questioning & $3(6)$ & $0(0)$ & $3(4)$ \\
\hline Two-spirit & $2(4)$ & $1(6)$ & $3(4)$ \\
\hline Otherף & $11(20)$ & $0(0)$ & $11(15)$ \\
\hline No response & $9(17)$ & $0(0)$ & $9(13)$ \\
\hline \multicolumn{4}{|l|}{ Sex work experience $\ddagger$} \\
\hline Agency escort & $25(46)$ & $7(41)$ & $32(45)$ \\
\hline Fetish & $14(26)$ & $4(24)$ & $18(25)$ \\
\hline Independent escort & $35(65)$ & $8(47)$ & $43(61)$ \\
\hline Massage parlour attendant & $10(18)$ & $1(6)$ & $11(15)$ \\
\hline Outdoor worker & $2(4)$ & $1(6)$ & $3(4)$ \\
\hline Pornography actor & $12(22)$ & $4(24)$ & $16(22)$ \\
\hline Stripper/exotic dancer & $6(11)$ & $4(24)$ & $10(14)$ \\
\hline Sugar baby & $17(31)$ & $12(71)$ & $29(41)$ \\
\hline Survival sex & $11(20)$ & $5(29)$ & $16(22)$ \\
\hline Webcam host & $22(41)$ & $5(29)$ & $27(38)$ \\
\hline Other & $1(2)$ & $1(6)$ & $2(3)$ \\
\hline \multicolumn{4}{|c|}{ 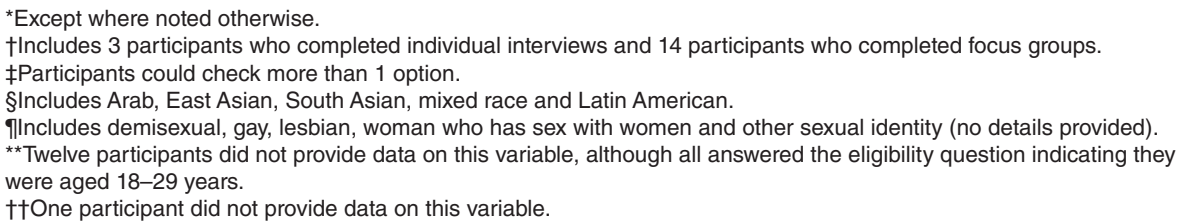 } \\
\hline
\end{tabular}


(32/48 [67\%]) reported having had bad experiences with health care services that made them not want to go back.

\section{Barriers}

Survey data regarding barriers and facilitators are provided in Table 2, with illustrative quotes presented in Table 3 . The most commonly reported barriers to accessing care were believing that health care providers judged sex workers (33 [61\%]), concerns about anonymity or confidentiality (33 [61\%]) and believing that health care providers would be uninformed or underinformed about sex work (32 [59\%]).

The quantitative findings were echoed in the qualitative data: the primary barrier identified was actual or expected health care provider stigma, manifesting in a variety of ways, including condescending attitude and resulting treatment, refusal to take seriously participants' self-reported sexual and reproductive needs, and efforts to convince participants to leave sex work without any acknowledgement of the complexities of their individual sex work experiences. Other reported barriers included costs associated with desired interventions (e.g., human papillomavirus vaccination), clinic forms and procedures that do not account for the realities of sex work, and intersecting forms of stigma (particularly ageism, sexism and ableism associated with psychiatric diagnoses participants had received).

\section{Facilitators}

Survey respondents indicated that staff and volunteers with sex work experience (41 [76\%]), nonjudgmental staff and volunteers $(38[70 \%])$ and an antioppressive space (38 [70\%]) would make them more likely to access sexual or reproductive health care services.

Key facilitators of access described in interviews and focus groups echoed the quantitative data: respectful, nonjudgmental service providers to whom participants felt they could disclose their sex work experience, access to services that are free or anonymous, and personal characteristics that they could leverage in health care encounters (e.g., assertiveness, knowledge of their own bodies).

\section{Practices suggested by participants}

Data from participants in the quantitative and qualitative strands regarding their recommended practices to improve access to sexual and reproductive health care services for young adult sex workers generated 7 suggested practices (Table 4). These practices collectively address barriers and facilitators identified at the provider level (e.g., adopting a nonjudgmental approach to working with sex workers) and barriers and facilitators at the system or service level (e.g., recruiting staff and volunteers with sex work experience).

\section{Interpretation}

In this community-based research study, we found that young adult sex workers in the Toronto area were likely to receive suboptimal reproductive and sexual health care given their actual and expected experiences of provider stigma, which, in turn, were associated with very low levels of disclosure of their sex work experience. For many participants, experiences with

\begin{tabular}{|c|c|c|}
\hline Barrier/facilitator & $\begin{array}{l}\text { No. of } \\
\text { participants }\end{array}$ & $\begin{array}{l}\% \text { of participants } \\
(95 \% \mathrm{Cl})\end{array}$ \\
\hline \multicolumn{3}{|l|}{ Barriers $(n=53)$} \\
\hline I think health care providers judge sex workers & 33 & $62(48.8-74.1)$ \\
\hline I am concerned about my anonymity/confidentiality & 33 & $62(48.8-74.1)$ \\
\hline I think health care providers are uninformed about sex workers & 32 & $60(46.9-72.4)$ \\
\hline I feel emotional distress, depression or anxiety & 29 & $55(41.4-67.4)$ \\
\hline $\begin{array}{l}\text { The cost of things I need for my sexual health, like birth } \\
\text { control, condoms or other prescriptions }\end{array}$ & 28 & $53(39.7-65.6)$ \\
\hline I am worried about my friends or family finding out & 27 & $51(37.9-63.9)$ \\
\hline \multicolumn{3}{|l|}{ Facilitators $(n=52)$} \\
\hline Staff and volunteers who have sex work experience & 41 & $79(65.8-87.9)$ \\
\hline Nonjudgmental staff and volunteers & 38 & $73(59.7-83.3)$ \\
\hline Antioppressive space & 38 & $73(59.7-83.3)$ \\
\hline $\begin{array}{l}\text { Knowing that I will not be reported to the police, social worker } \\
\text { or child protection services for my involvement in sex work }\end{array}$ & 32 & $62(47.9-73.6)$ \\
\hline $\begin{array}{l}\text { Staff and volunteers who are similar to me (e.g., in age, gender } \\
\text { identity, sexual identity, race) }\end{array}$ & 25 & 48 (35.1-61.3) \\
\hline Convenient location & 20 & $38(26.5-52.1)$ \\
\hline
\end{tabular}


Table 3: Illustrative quotes from qualitative data analysis regarding barriers to and facilitators of accessing sexual and reproductive health care

Theme; subtheme Illustrative quote

\section{Barriers}

Provider stigma

Interviewer: What was it like [when you disclosed your sex work experience]?

Participant: Incredibly aggravating, frustrating, offensive. I felt like it was someone's mother scolding me. I felt incredibly judged ... I didn't seem to matter. So when I had questions, they [health care provider] were very vague and unresponsive. Almost like I wasn't even there. (Focus group 4)

Cost of interventions

I did get my first round of HPV shots last week. It was disgustingly expensive. I had to pay about $\$ 215$... I called several health outlets, and all of them [said] unless you're a student in high school or you have some sort of coverage as a postsecondary student [you have to pay out of pocket]. (Focus group 3 )

Clinic forms and procedures

I try to get tested every 3 months. And there have been times and different facilities, particularly the [sexual health clinic], where they seem to be a little critical of coming so frequently, and they ask why. Which feels like a bit of a judgment, when I'm having as much as I'm having. But I've stopped going there as a result. (Interview 3)

Intersecting stigmas

I never actually told any doctor that l've spoken to that I'm a sex worker for many, many reasons. Including the fact that I live with PTSD, and the minute you tell somebody that you're somebody who suffers from PTSD, and that you're a sex worker, you can no longer make decisions for yourself as an adult in the medical community. (Focus group 3 )

\section{Facilitators}

Respectful, nonjudgmental service providers

Interviewer: Could you explain what made [the service encounter] a positive experience, if you can recall how the person responded, or what made you feel comfortable telling them [about your sex work experience] in the first place?

Participant: Just right off the bat ... the tone was very calm and welcoming, so I knew that there was never any hostility in terms of the environment and initial responses. It just felt very casual. ... I would just say, "Oh, I'm a sex worker, this is how many partners I've had" ... while we're doing testing ... just so they could learn my history. But it was just a lot of ... "Oh, I see," nodding, asking if I was being safe ... the precautionary questions that they have to [ask] everyone. But ... I think the tone was the biggest factor, and facial expressions. (Interview 1)

Access to free, anonymous services

I know [name of service, where], for homeless youth, there's free doctors. You don't have to show ID. ... That's where I was most comfortable going to get tested, rather than going to my family doctor. So things like those - walk in, where you know the doctor's there from 1 to 4 , and ... they don't really know who you are. I think that you're more inclined to be honest [about sex work experience] because they don't know who you are, but you're getting the treatment that you need, if you need treatment. And you don't feel as judged, I guess. (Focus group 1)

Personal characteristics

Once they [health care provider] speak to me for a couple of minutes, any sort of stigma that they probably typically have and would hold onto in other situations subsides. So I am fully aware of that privilege. I think that's exactly what it is. And l've even had friends that have come over here, from Russia and the Ukraine, that fall into [sex work] because they're just trying to get things in order for themselves and can't qualify for other jobs. They themselves, who are highly educated, much more than I am, they deal with attitude when they see a doctor, and it can be the same person who I saw maybe 2 days before and had a wonderful experience with. ... I think that l'm lucky in a way ... I can be very assertive and I'm never shunned. But if I were not who I am ... I'd have a very different outcome. I don't doubt that for a second. (Focus group 3)

Note: $\mathrm{HPV}=$ human papillomavirus, ID = identification, $\mathrm{PTSD}=$ post-traumatic stress disorder. 
Table 4: Participant-recommended practices to improve service delivery

\begin{tabular}{|c|c|}
\hline Recommended practice & Illustrative quote \\
\hline $\begin{array}{l}\text { Adopt a nonjudgmental approach to } \\
\text { working with sex workers }\end{array}$ & $\begin{array}{l}\text { So it's just really about education and ... not judging a book by its cover, and I } \\
\text { think that'll make the girls feel a lot more open. ... If they know ... there's so many } \\
\text { different reasons I could be doing it [sex work], and they're not going to judge me, } \\
\text { they're just going to help me. (Focus group 1) }\end{array}$ \\
\hline $\begin{array}{l}\text { Become familiar with the social } \\
\text { realities of sex work }\end{array}$ & $\begin{array}{l}\text { What I would like to see from a medical institutional framework or standpoint } \\
\text { would be an understanding of the social context of sex work. So I would like to } \\
\text { see an institution come out and say, "We understand that sex workers want } \\
\text { decriminalization, that sex workers deserve rights, and labour rights, and human } \\
\text { rights, that are lacking at this time." I would like to see an explicit kind of support } \\
\text { of that from an institution that I go to. (Interview 3) }\end{array}$ \\
\hline $\begin{array}{l}\text { Make your work place accessible for } \\
\text { sex workers }\end{array}$ & $\begin{array}{l}\text { [A local sexual health clinic] is great but is hard to get to if I'm not downtown. } \\
\text { [Local public health] clinics don't have the greatest times and are often full. } \\
\text { (Survey respondent) }\end{array}$ \\
\hline Provide appropriate services & $\begin{array}{l}\text { A sexual health clinic insisted I must be having unprotected sex when I stated I was } \\
\text { not, and tried to convince me to leave the industry because I seemed tired and } \\
\text { stressed (I'm a student, of course I seem tired and stressed). (Survey respondent) }\end{array}$ \\
\hline $\begin{array}{l}\text { Publicly voice your position on sex } \\
\text { work }\end{array}$ & $\begin{array}{l}\text { I want to know from the get-go .... that they [the doctor] were sex positive and they } \\
\text { were sex work positive. ... I don't need someone that doesn't get it or that's really } \\
\text { conservative in their mindset. (Interview 2) }\end{array}$ \\
\hline $\begin{array}{l}\text { Recruit staff and volunteers with sex } \\
\text { work experience }\end{array}$ & $\begin{array}{l}\text { Survey question: What are your sources of strength and resilience? } \\
\text { Respondent: Being around others working in this industry. }\end{array}$ \\
\hline $\begin{array}{l}\text { Understand the diversity of sex work } \\
\text { experiences }\end{array}$ & $\begin{array}{l}\text { Knowing that people in this industry are literally from all walks of life. Some girls } \\
\text { are doing it for survival. Some girls are doing it to get through school. Some girls } \\
\text { are doing it because they're into sex.... I have one girl that I used to work with and } \\
\text { her dad worked in the parliament buildings.... She didn't need to be working, she } \\
\text { just loved to work. That was her thing. And she went to [university], and it was just } \\
\text { her extra money ... that's what she liked to do, and there was nothing wrong with } \\
\text { that. So just knowing that ... we're not all ... damaged, and because I think a lot of } \\
\text { people think, "Oh my gosh, if I tell the doctor this, they're going to think I have } \\
\text { daddy issues, or I've been - something's happened to me, traumatic, that this is } \\
\text { why l'm here.. It's not always like that. ... You could just be going through school, } \\
\text { and it's [income from sex work] helpful. (Focus group 1) }\end{array}$ \\
\hline
\end{tabular}

provider stigma regarding sex work led them to conclude that disclosure of their experience would do more harm than good with respect to being able to have their sexual and reproductive health needs met. Linking back to the social justice framing of our study, these findings suggest that the stigma surrounding sex work that predominates in Canadian society may often be held by health care providers and, as result, is a key contributor to access to suboptimal sexual and reproductive health care for young adult sex workers. ${ }^{4}$

Our findings align with previous literature describing access to suboptimal care and stigma-related barriers to care for people involved in sex work, ${ }^{3,17,18}$ and extends this literature to include young adult sex workers in particular. For example, in a study of more than 200 sex workers in 5 Canadian metropolitan areas, sex workers reported almost 3 times the rate of unmet health care needs as the general Canadian population. ${ }^{19}$ Furthermore, a Canadian study indicated that young sex workers are more likely than their adult counterparts to be homeless, to inject heroin daily and to service clients in public places. ${ }^{20}$ Another study showed that young male adult sex workers were more likely to engage in sexual practices that elevate HIV exposure than their street-involved counterparts who did not engage in sex work. ${ }^{21}$
Our results also align with prior research identifying provider stigma associated with sex work as a primary barrier to health care access for this population. ${ }^{3,4,22}$ Our finding that many young adult sex workers reported that they chose not to disclose their sex work involvement to health care providers is also consistent with previous studies, ${ }^{4,23}$ in particular literature indicating that sex workers with additional stigmatizing identities (in this case, youth) were particularly unlikely to disclose. ${ }^{23}$ Given that prior research has established long-term impacts of negative experiences with health care on sex workers' future decisions to seek care when needed, ${ }^{4}$ these experiences of young adult sex workers may have lasting health impacts well into adulthood.

Our finding that providers' perceived stigma and lack of knowledge about sex work are primary barriers to access to sexual and reproductive health care for this population suggests that provider education and training — including stigma reduction - and subsequent communication to the sex work community about improved provider competency could be important mechanisms to improve access. We were unable to identify any research initiatives to assess inclusion of sexwork-related content in medical curricula. Research from the provider's perspective will be necessary to identify specific gaps to be addressed by such initiatives, as well as to determine 
the best timing (e.g., during training or as continuing education) and forum (e.g., didactic or arts-based, among others). Given that our study identified involvement of people with sex work experience as a primary facilitator of health care access, involving the sex work community in the development and delivery of these interventions will be important.

The finding that many young adult sex workers reported that they chose not to disclose their involvement in sex work to their provider also has concerning implications for the quality of care they are likely to receive: Benoit and colleagues $^{23}$ found that sex workers were more likely to experience benefits than harms of sex work disclosure. Thus, for organizations that have developed capacity to provide competent care to sex workers, community outreach efforts to encourage disclosure may be warranted.

\section{Limitations}

Given that this study was driven by local needs, it included only young adult sex workers who lived or worked in the Toronto area; thus, we did not capture the experiences of those working in other settings where sex work and health care access may operate differently, particularly more rural and remote settings. Additional research is needed to understand the experiences of these young adult sex workers in accessing health care. We included people who had previous sex work experience in our sample, both in order to hear from those who were involved in sex work before age 18 years and in recognition that, for many, sex work is not a full-time permanent job, and people often go through periods where they do not work (e.g., during pregnancy and in varying times of economic need). There may be differences in the health care needs and experiences between those with current versus previous sex work experience; however, given that there was about 5 years' difference between participants' current ages and the ages at which they first engaged in sex work, all participants had relatively recent involvement in sex work.

Our study had limited inclusion of outdoor sex workers. The online nature of our survey, primary recruitment and screening methods, as well as the timing of our study (data were collected during the winter months) may have contributed to underrepresentation of outdoor sex workers, who may have different sexual and reproductive health care needs and experiences than other sex workers. However, although representative data are difficult to collect owing to the hidden and criminalized nature of sex work, a 2006 Canadian federal government report suggested that only $20 \%$ of sex workers work outdoors. ${ }^{24}$ This proportion may have since decreased owing to the growth of online sex work. ${ }^{25}$

We used a broad definition of sexual services that is consistent with current Canadian legislation, ${ }^{26}$ but it is likely that different groups of sex workers within this broad definition (e.g., indoor v. outdoor workers) have different experiences with accessing sexual and reproductive health care services. Thus, future research focusing on 1 or more particular groups of sex workers is warranted. However, given that prior research has identified a focus on outdoor workers to the exclusion of other sex workers as a limitation of much research in this field, ${ }^{4}$ our inclusion of a broad range of sex workers could also be considered a strength of this research.

In the qualitative strand of our research, data collection and analysis were not iterative for feasibility reasons. However, data saturation was achieved with respect to the primary themes (i.e., barriers, facilitators and recommended practice changes), given that no new major themes were identified during a final meeting of the entire coding team on analysis of the last round of transcripts. Given that these findings were triangulated with the quantitative data (i.e., primary barriers and facilitators were the same in each strand of data), we were further confident that thematic saturation had been reached.

\section{Conclusion}

Our findings offer insights into the experiences of young adult sex workers in accessing sexual and reproductive health care. They suggest that interventions to address provider knowledge and attitudes regarding sex work are necessary as one mechanism to address sex work stigma in order to improve access to health care services for sex workers. Future research is warranted to explore these and other mechanisms for ensuring equitable access to sexual and reproductive health care for those who engage in sex work.

\section{References}

1. Sex work in Canada: the public bealth perspective. Ottawa: Canadian Public Health Association; 2014. Available: www.cpha.ca/sites/default/files/assets/policy/sex -work_e.pdf (accessed 2019 Dec. 11).

2. UNAIDS welcomes the decision by the Northern Territory of Australia to decriminalize sex work [news release]. Geneva: UNAIDS; 2019. Available: www.unaids.org/en/resources/presscentre/pressreleaseandstatementarchive/ 2019/december/decision-northern-territory-australia-decriminalize-sex-work (accessed 2019 Dec. 11)

3. Lazarus L, Deering KN, Nabess R, et al. Occupational stigma as a primary barrier to health care for street-based sex workers in Canada. Cult Health Sex 2012;14:139-50.

4. Benoit C, Jansson SM, Smith M, et al. Prostitution stigma and its effect on the working conditions, personal lives, and health of sex workers. 7 Sex Res 2018; 55:457-71.

5. Shannon K, Bright V, Gibson K, et al. Sexual and drug-related vulnerabilities for HIV infection among women engaged in survival sex work in Vancouver, Canada. Can 7 Public Health 2007;98:465-9.

6. Workowski KA. Centers for Disease Control and Prevention sexually transmitted diseases treatment guidelines. Clin Infect Dis 2015;61(Suppl 8):S759-62.

7. Global health sectors strategy on sexually transmitted infections 2016-2021: towards ending STIs. Geneva: World Health Organization; 2016. Available: https:// apps.who.int/iris/bitstream/handle/10665/246296/WHO-RHR-16.09-eng.pdf; jsessionid=441D56D16ACB44B0F0D398D9D5D92C47? sequence=1 (accessed 2019 Dec. 11).

8. Sexually transmitted infections (STIs) [news release]. Geneva: World Health Organization; 2019 June 14. Available: www.who.int/news-room/fact-sheets/ detail/sexually-transmitted-infections-(stis) (accessed 2019 Dec. 11).

9. Youth sexual health needs assessment 2015-2016. Toronto: Planned Parenthood Toronto; 2016.

10. Street needs assessment 2018: results report. Toronto: City of Toronto; 2018. Available: https://www.toronto.ca/wp-content/uploads/2018/11/99be-2018 -SNA-Results-Report.pdf (accessed 2021 Apr. 22).

11. von Elm E, Altman DG, Egger M, et al.; STROBE Initiative. The Strengthening the Reporting of Observational Studies in Epidemiology (STROBE) statement: guidelines for reporting observational studies. Lancet 2007;370:1453-7.

12. Tong A, Sainsbury P, Craig J. Consolidated criteria for reporting qualitative research (COREQ): a 32-item checklist for interviews and focus groups. Int 7 Qual Health Care 2007; 19:349-57.

13. Eysenbach G. Improving the quality of Web surveys: the Checklist for Reporting Results of Internet E-Surveys (CHERRIES). 7 Med Internet Res 2004;6:e34

14. Wallerstein N, Duran B, Oetzel JG, et al., editors. Community-based participatory research for bealth: advancing social and bealth. 3rd ed. San Francisco: Jossey-Bass; 2017.

15. Mertens DM. Transformative mixed methods research. Qual Inq 2010;16:469-74.

16. Braun V, Clarke V. Using thematic analysis in psychology. Qual Res Psychol 2006;3:77-101. 
17. Bungay V, Kolar K, Thindal S, et al. Community-based HIV and STI prevention in women working in indoor sex markets. Health Promot Pract 2013;14:247-55.

18. Kurtz SP, Surratt HL, Kiley MC, et al. Barriers to health and social services for street-based sex workers. F Health Care Poor Underserved 2005;16:345-61.

19. Benoit $\mathrm{C}$, Ouellet $\mathrm{N}$, Jansson $M$. Unmet health care needs among sex workers in five census metropolitan areas of Canada. Can 7 Public Health 2016;107:e266-71.

20. Miller CL, Fielden SJ, Tyndall MW, et al. Individual and structural vulnerability among female youth who exchange sex for survival. 7 Adolesc Health 2011; 49:36-41.

21. Haley N, Roy E, Leclerc P, et al. HIV risk profile of male street youth involved in survival sex. Sex Transm Infect 2004;80:526-30.

22. Logie CH, James L, Tharao W, et al. Gender, race, sexual orientation, and sex work: a qualitative study of intersectional stigma experienced by HIV-positive women in Ontario, Canada. PLoS Med 2011;8:e1001124.

23. Benoit C, Smith M, Jansson M, et al. Canadian sex workers weigh the costs and benefits of disclosing their occupation status to health providers. Sex Res Social Policy 2019;16:329-41.

24. The challenge of change: a study of Canada's criminal prostitution laws. Report of the Standing Committee on Justice and Human Rights. Ottawa: House of Commons; 2006. Available: www.ourcommons.ca/DocumentViewer/en/39-1/ JUST/report-6 (accessed 2019 Dec. 11).

25. Sanders T, Scoular J, Campbell R, et al. Internet sex work: beyond the gaze. London (UK): Palgrave MacMillan; 2018.

26. Protection of Communities and Exploited Persons Act (S.C. 2014, c. 25). Available: https://laws.justice.gc.ca/eng/AnnualStatutes/2014_25/FullText.html (accessed 2020 Nov. 30).

Affiliations: Dalla Lana School of Public Health (Ross, D'Souza), Centre for Criminology and Sociolegal Studies (Sterling) and Factor-Inwentash Faculty of Social Work (Logie), University of Toronto; Planned Parenthood Toronto (Dobinson); Toronto, Ont.

Contributors: Cheryl Dobinson conceived of the study. Lori Ross and Cheryl Dobinson designed the study. Lori Ross, Andrea Sterling, Cheryl Dobinson and Carmen Logie analyzed the data. Lori Ross drafted the manuscript. Andrea Sterling, Cheryl Dobinson, Carmen Logie and
Sandra D'Souza revised the manuscript for important intellectual content. All of the authors interpreted the data, approved the final version to be published and agreed to be accountable for all aspects of the work.

Funding: This project was funded by the Women's College Hospital Women's Xchange program. Carmen Logie is supported by the Canada Research Chairs Program, Ontario Ministry of Research \& Innovation, and Canada Foundation for Innovation. Andrea Sterling is supported by a Vanier Canada Graduate Scholarship.

Content licence: This is an Open Access article distributed in accordance with the terms of the Creative Commons Attribution (CC BY-NC-ND 4.0) licence, which permits use, distribution and reproduction in any medium, provided that the original publication is properly cited, the use is noncommercial (i.e., research or educational use), and no modifications or adaptations are made. See: https://creativecommons.org/licenses/by-nc-nd/4.0/.

Data sharing: For the protection of our research participants and in compliance with our research ethics protocol, none of the data are available to people outside of the research team.

Acknowledgements: The authors sincerely acknowledge the following people, who made invaluable contributions to this work: the research participants; the Youth Advisory Committee members, including Antoine Ammiro, Bree Daniels, Jenny Duffy and Azura Rose; the study partners at Maggie's Toronto Sex Workers Action Project, including Monica Forrester, Jennifer Porter and Severin Leal; and Olivia Taylor, for editorial assistance with the manuscript.

Disclaimer: The funders had no role in the collection, analysis, interpretation or dissemination of the study data.

Supplemental information: For reviewer comments and the original submission of this manuscript, please see www.cmajopen.ca/content/9/2/ E482/suppl/DC1. 